\title{
Challenges of Increased Wind Energy Penetration in Ireland
}

\author{
Morgan Bazilian \\ Dept Head - Sustainable Energy Services, \\ Sustainable Energy Ireland, \\ Glasnevin, \\ Dublin 9, \\ Ireland. \\ Tel: + 35318082075 , \\ Fax: + 35318372033 , \\ E-mail:morgan.bazilian@sei.ie
}

\author{
Eleanor Denny \\ Dept. Electronic \& \\ Electrical Engineering, \\ University College Dublin, \\ Belfield, Dublin 4, \\ Ireland. \\ Tel: +353(0)1 7161857 \\ Fax: $+353(0) 12830921$ \\ E-mail: eleanor.denny@ucd.ie
}

\author{
Mark O'Malley \\ Dept. Electronic \& \\ Electrical Engineering, \\ University College Dublin, \\ Belfield, Dublin 4, \\ Ireland \\ Tel: +353 (0)1 7161851 \\ Fax: +353 (0)1 2830921 \\ E-mail:mark.omalley@ucd.ie
}

\section{ABSTRACT}

Ireland is a facing a critical time in the formation of a robust renewable energy (RE) policy, due to its size, relative isolation, grid infrastructure, and fuel import dependency. Wind's inherent intermittency and unpredictability make its increased penetration into the electricity network an area requiring significant further analysis. This paper follows a colloquium entitled "On the Technical Challenges of Increasing Wind Energy Penetration in Electricity Networks" held in Dublin in March 2003 to raise the level of dialogue on the subject in Ireland. The colloquium encompassed sessions on modelling and design of wind farms, grid requirements and wind penetration studies. This paper details the current state of the Irish electricity system, describes the status of the electricity market and puts into perspective the technical isssues which need to be resolved to increase wind penetration on the island of Ireland.

\section{INTRODUCTION}

There is an implicit assumption in most European countries that there is a need to support increased penetration of wind electricity generation. The reasons and levels of support vary widely. Renewable energy (RE) policy must be formed within the wider context of energy policy. It must therefore address similar pressures to meet Ireland's energy requirements, in an environmentally and economically sustainable way while having regard for forecast economic growth and security of supply objectives [1].

The technical obstacles to further wind penetration on an essentially island network have been predominantly identified. These issues range from concerns about low voltage ride-through and frequency control to voltage and power factor control. Accurate wind forecasting in varying timescales will be critical for optimal dispatch and planning of operating reserves. Addressing these issues requires a high level of technical knowledge of wind generators and their associated power electronic interfaces as well as power system operation. Grid codes will also need to explicitly and fairly treat the unique operational aspects of wind power, however, these grid codes should not place any more onerous distortions on the efficient operation of the system than other interests. It is essential to provide robust solutions to all of these concerns in order to mitigate decreased system security and reliability.

Existing targets for renewable energy stem from national, European Union, and other international policy commitments including:

- $\quad$ EC Directive [2] sets a national indicative target for Ireland of a contribution from renewables of $13.2 \%$ of gross electricity consumption by 2010 ;

- EU White Paper indicative target for the Community of achieving $12 \%$ of gross domestic energy consumption from renewable energy by 2010 [3].

- Green Paper on Sustainable Energy target for Ireland of an additional 500 Megawatts (MW) of Renewable Energy generating capacity by 2005 [1];

- National Climate Change Strategy target of reducing annual Carbon Dioxide $\left(\mathrm{CO}_{2}\right)$ emissions by 1 Megatonne (Mt) from a 'Business As Usual' case through increased deployment of renewable energy [4].

The salient points in the EC Directive [2] for this discussion are found in Article 7, which states the necessity for the Transmission System Operator (TSO) and Distribution System Operator (DSO) to guarantee the transmission and 
distribution of, and granting priority dispatch for, renewable energy sources (insofar as the national electricity system permits).

There is approximately $165.5 \mathrm{MW}$ of wind energy in the Republic of Ireland at present, with an additional $18.7 \mathrm{MW}$ under construction at the time of writing and nearly 450MW of projects with full electricity network connection agreements. This $400 \mathrm{MW}$ includes two offshore projects $(25 \mathrm{MW}$ connecting to the $38 \mathrm{kV}$ and $60 \mathrm{MW}$ connecting at $110 \mathrm{kV}$ ) on the southeast coast near Arklow. Of the $165.5 \mathrm{MW}$ of wind energy already in operation, the majority is connected to the distribution network. In Ireland, efforts have previously focused on surmounting planning hindrances. In May, 2003 there were 1,231 MW of wind energy with full planning permission, and 1,341 MW awaiting local authority decisions.

The Alternative Energy Requirement (AER) is the principle vehicle for providing fiscal support for renewable energy implementation in Ireland. It is a competitive bidding process for power purchase agreements. The government administers the programme by periodically inviting tenders for specified amounts and types of renewable electricity or Combined Heat and Power capacity from private developers and determining cap prices. Contracts are awarded to the winning tenders and the Public Electricity Supply (PES) division of the Electricity Supply Board (ESB) is obliged to contract to purchase all of the output for a 15 -year period.

The AER VI competition closed on the 24 April 2003. There were three categories offered for wind energy: largescale onshore (with a price cap of 5.216 eurocent per kilowatt hour (kWh)), small-scale onshore (price cap - 5.742 eurocent per $\mathrm{kWh}$ ), and offshore (price cap - 8.400 eurocent per $\mathrm{kWh}$ ). The AER VI prices are fully indexed to the Consumer Price Index and there is an option for an accelerated $(+35 \%)$ payment in the first 7.5 years (with a corresponding step down). On 9 July 2003, it was announced that a total of $329.42 \mathrm{MW}$ were awarded in contracts to wind energy [5]. Project sizes ranged from $0.85-60.35 \mathrm{MW}$.

ESB PES is allowed to collect the premium paid for AER contract generation above the Commission for Energy Regulation's (CER) designated best new entrant price (approximately $€ 48$ per Megawatt hour (MWh)[6]) from consumers through a public service obligation levy on all electrical bills. This mechanism was put in place primarily to support the continued operation of peat-fired thermal generation plants. If the costs (including collection charges) are split in a weighted fashion, in 2004 , peat will account for $78 \%$ of the public service obligation levy while AER purchases will account for $22 \%$ [7].

Fiscal support mechanisms can be categorised as operating either by incentivising the supply side or the demand side. In the future Ireland may introduce support mechanisms seen in other countries such as: Feed-in tariffs (fixed or advanced), competitive tender mechanisms, production tax credits (in the USA), renewables obligation with tradable renewable certificates such as Renewable Obligation Certificates, Renewable Energy Certificates, Tradable Renewable Certificates, etc. These mechanisms have had varying degrees of success, costs, and impacts on competitive electricity markets (as well as implementation rates and societal burdens/opportunities). These instruments interact with secondary support measures including indirect price support through carbon taxes or emissions trading, and capital support through grants, tax incentives that are beyond the scope of this paper.

\section{ELECTRICITY SUPPLY}

The conversion efficiency of electricity supply in Ireland, which is defined as final consumption of electricity divided by the fuel inputs required (the calorific value of the fuel) is shown in Fig. 1 [8]. The fuel input is net of inputs from renewable sources, the generation plants 'own use' of electricity and transmission and distribution losses. It is also useful for context to have the average emissions factor for electricity generation (Fig. 2)[8]. 
Fig. 1:

Conversion efficiency of electricity supply in Ireland

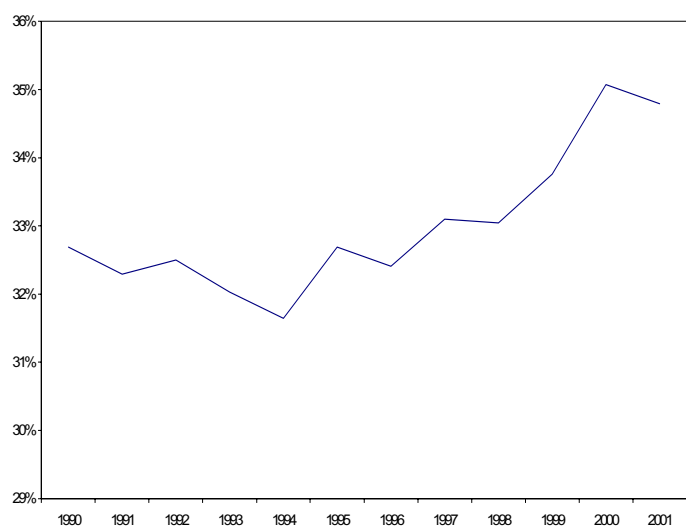

Fig. 2:

$\mathrm{CO}_{2}$ emissions factor for electricity supply in Ireland

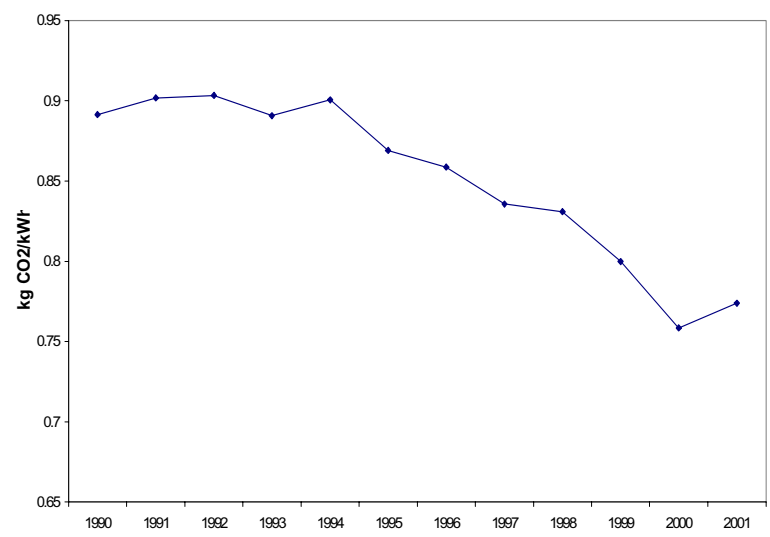

Energy production and consumption was responsible for $66 \%$ of Ireland's total Greenhouse Gas emissions in 2001. Energy related $\mathrm{CO}_{2}$ emissions in 2001 were 44\% higher than 1990 levels. Renewable sources of energy provided around $1.8 \%$ (including large-scale hydro) of Ireland's total primary energy requirement in 2000 (the majority of which was from biomass). Renewables contributed around 5\% of gross electricity production over most of that period. Wind energy and landfill gas generation only accounted for about $1.5 \%$ of gross electricity production in 2001 . Renewable energy production displaced the equivalent of $0.65 \mathrm{Mt} \mathrm{CO}_{2}$ in 1990 , which rose to $0.83 \mathrm{Mt}$ in 2001 .

Key to any electricity system is the security of energy supply. Helm [9] notes that security of supply can be addressed in three discrete areas: supply (contracting) security, network (wires and delivery) security, and as a function of diversity of fuel supply (or generation). It has been widely theorised that wind energy can have benefits in the security of supply arena due to its inherent indigenous nature, renewable and free fuel supply, short construction times, and distributed nature.

The Transmission System Operator's Generation Adequacy Report [10] discusses the Irish approach to determining the adequacy of the present generation assets. The Statement forecasts electricity generation shortfalls from 2003 to 2009. Also since mid 2002 the availability of the portfolio of generation plant connected to the Irish power system has been deteriorating [11]. In figure 3 below, each point on the graph represents the average weekly system availability that has been experienced over the previous 52-week period. As the points represent an average value calculated over a significant period (52 weeks), any short-term volatility in availability is effectively damped out, thus allowing true underlying trends to be examined [11].

Fig. 3: A moving average of weekly system availability [11] Fig. 4: Forced Outage Rates in Ireland since 1997 [11]
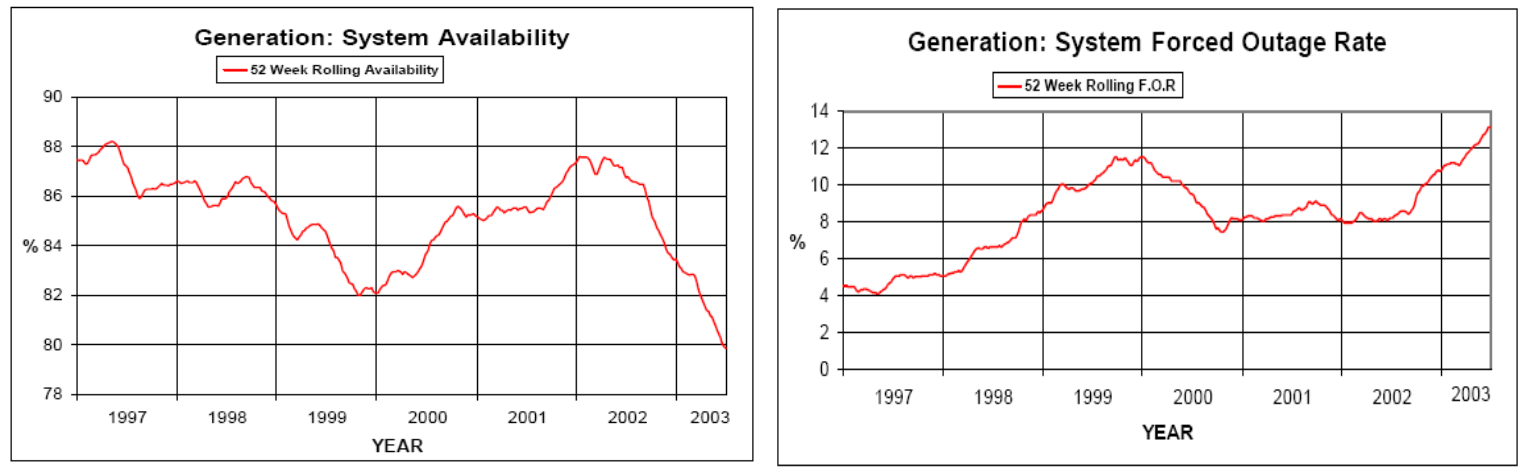

Irish forced outage rates are now at their worst level for more than 20 years [11]. This rapid worsening of forced outage rates has major implications for the ability of the power system to meet peak demand. Figure 4 above shows the Irish system forced outage rate over the past six years. This reduction in performance is occurring at a time when there is already a significant and worsening deficit of generation capacity. 
Every three years the World Energy Council publishes performance statistics for international generation plants. The latest report, in 2001, provides the following performance figures for thermal generation plant [11].

Table 1: International forced outage rates

\begin{tabular}{lcccc}
\hline & $\mathbf{1 9 9 7}$ & $\mathbf{1 9 9 8}$ & $\mathbf{1 9 9 9}$ & Average \\
\hline Europe & 4.6 & 4.0 & 5.6 & 4.7 \\
North America & 6.1 & 6.3 & 6.2 & 6.2 \\
\hline
\end{tabular}

It is clear by comparing figure 4 with the data in table 1 that Ireland is seriously lagging behind international forced outage rate standards.

The entry of a considerable amount of new conventional generation to the market is anticipated and indeed required. The generation plant mix will depend upon the influence of specific drivers in the electricity market. If the trading environment creates an incentive through uncapped electricity prices, the entry of short-run open-cycle plant to the market could become more prevalent. Larger amounts of wind generation would give further incentive for this type of plant to occupy a niche in compensating for wind power variability.

In Ireland the summer minimum is only $35 \%$ of the winter peak [12] and when coupled with the inability of much of the older base load plant to be severely powered down places a limit on wind power.

Hurley [13] has simulated the power output from a $1 \mathrm{GW}$ penetration of wind energy in Ireland. A rate of occurrence histogram (Fig. 5) was produced to inform the discussion on the impacts on system operation and the possible need for constraining the wind power output. It is useful to note that at certain times of the year it is predicted that the ratio of wind power to system demand could exceed $60 \%$.

Fig. 5: Relative rate of occurrence of the ratio of wind power to system demand in Ireland [13].

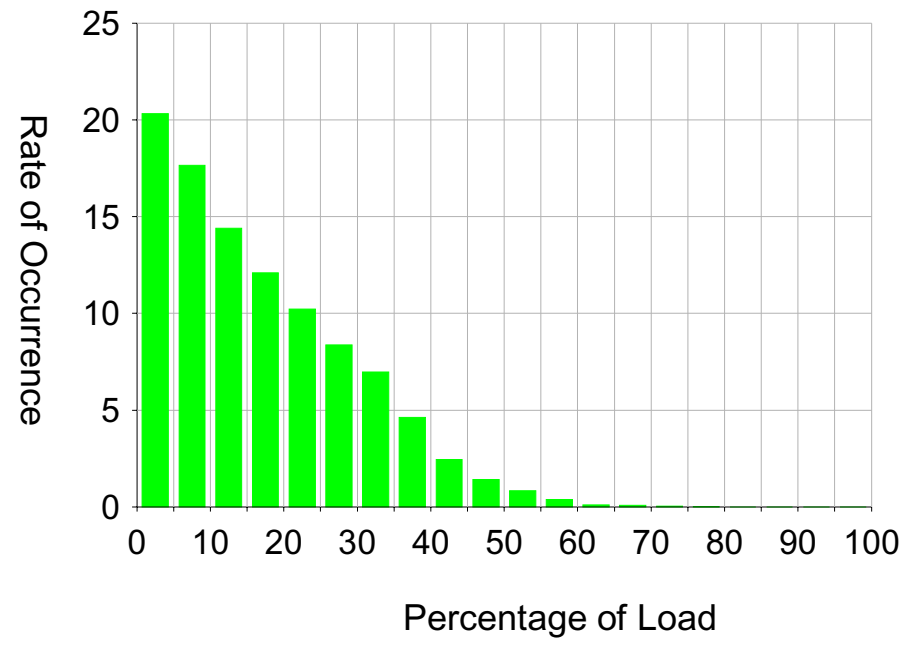

Ireland has a very large energy import dependency. It is significantly greater than the EU as a whole (roughly $87 \%$ versus 50\%[8]). In light of the goals of the National Climate Change Strategy an increased dependency on natural gas in the power sector will be evident. Ireland's import dependency has grown from $65 \%$ since 1990 [8]. This reflects the declining natural gas resource at the Kinsale field (Fig. 6), however, current exploration for oil and natural gas at Dooish, off the northwest coast, and estimated reserves of approximately $28.3 \times 10^{9}$ cubic metres of natural gas at the Corrib gas field may well change this scenario in the short to medium term. 
Fig. 6: Indigenous energy production in Ireland in (millions of tonnes of oil equivalent) [8].

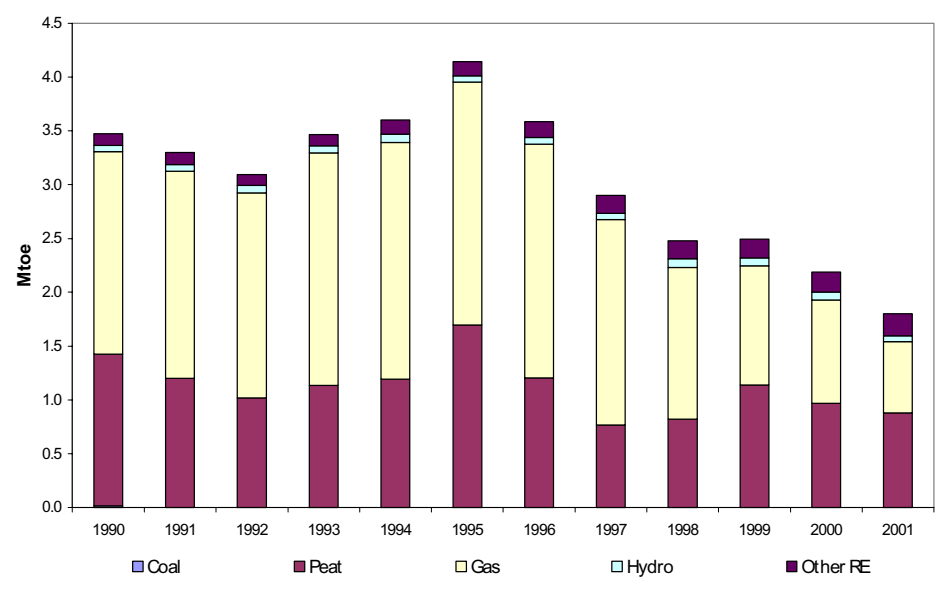

Ireland currently has limited interconnection capacity. Interconnection between Northern Ireland and the Republic of Ireland comprises a double circuit $220 / 275 \mathrm{kV}$ link between Tandragee and Louth. This interconnector has 600 Megavoltamps (MVA) of capacity, although actual transfer capacity is significantly less. There are also two $110 \mathrm{kV}$ lines between Letterkenny and Strabane, and Enniskillen and Corraclassy that are used for system support with no net trade. There is also some access to the 500MW High Voltage Direct Current (HVDC) interconnector through Northern Ireland to Scotland. A further East-West HVDC interconnector with the UK is under consideration. The CER commissioned a cost and benefits analysis study of the implications of inter-connector capacity on the Irish electricity system [14]. With the current increasing environmental pressures and the initiation of carbon emission taxes, it is likely that wind generation will move up the dispatch merit order as conventional plants become more expensive. The study found that in the presence of an interconnector this movement of wind generation up the merit order is still likely to occur. Utilisation of interconnectors will also have implications for the possibility of importing and exporting 'green power'.

\section{THE ELECTRICITY MARKET}

The impetus for electricity market liberalisation in Ireland stems from the commitment stated under section 9(1)a of the 1999 Electricity Regulation Act [15] (as well as the EC directive on Common Rules for the Internal Electricity Market [16]). There are wide ranges of political, social, and economic pressures that are placed on all market structures and the proposed electricity market is no exception.

The operation of the electricity system is intricately tied to the market structure. The market must ensure the secure operation of the system and quality of electricity supply is maintained. Arnott [17] has distilled the essential items for maintaining a robust power system through a market structure. These include: maintaining the power system frequency (under-frequency is the main concern for Ireland [18]), the voltages on the main transmission systems, and the main transmission systems within limits.

Wind generation can cause significant operational issues for the system operator. Many studies to date have focused on a fuel saver operational approach whereby the system is dispatched as though no wind generation were available and then if the wind power is available the conventional plant which is on, is deloaded (but never switched off) to make way for the wind generation. This is a highly conservative approach to system operation and is potentially costly with many plants running at low efficiencies. However, it does have the benefit that since there are many plants on, ancillary service provision should not be a burden.

Under the 1999 Electricity Regulation Act [15], special consideration was given to renewable electricity suppliers in granting them access to all consumers in advance of full market opening. Renewable electricity generators and suppliers are also advantaged in that they are only required to balance aggregated annual renewable electricity supply and demand (net green sales) to qualify as a "green" electricity supplier, rather than that for each half-hour metering and trading period [19]. However, in a particular trading period green retailers must top up with brown energy if they are not generating enough, and spill if they generate too much. The top-up price is always greater than or equal to the spill price. 
The base level price or "spill price", which non-dispatchable electricity generators can command, when selling their electricity within the electricity market without a supply contract creates a floor for renewable energy generated electricity. The current estimated best new entrant avoidable fuel price, and hence the spill price floor, is $€ 28 / \mathrm{MWh}$ [20].

On 12 September 2003 the Commission for Energy Regulation (CER) published a proposed decision on the market structure, with a view to market opening on 19 February 2005 [21]. The decision is based on "high-level principles", and thus does not specify details on the implementation of what is intended to be a centralised pool market through which all electricity must be bought and sold. The new market will have locational marginal pricing on the generation side and an average demand side price. In the Irish system, losses are likely to increase the price of generation in rural areas and since wind generation is predominantly cited in rural areas it is likely that it will be able to take advantage of these higher prices. It will be an energy only market (no capacity payments), with market clearing and dispatch determined every half hour. The supply of operating reserves will be co-optimised with the energy market, however, it is, as yet, unclear how this will be achieved. It is worth noting that the regulator is to have regard for the need to, promote the use of renewable, sustainable or alternative forms of energy.

The new market will offer wind generators a guaranteed market for energy as price takers, as they have a short run marginal cost of zero. It will eliminate the necessity of an asymmetric top-up and spill regime (as opposed to the New Electricity Trading Arrangements (NETA) in the UK), and allow for price transparency. However, there will still need to be research undertaken to explicitly address in detail how renewable energy plants are dispatched, ancillary services are paid for (or other treatment), pricing for non-dispatchable generators, and the use of financial hedging tools (such as Contracts for Differences (CfDs) and Financial Transmission Rights (FTRs)).

Research in the area of wind in competitive electricity markets is relatively sparse due the recent movement to electricity market restructuring in conjunction with: novel technological advances in wind turbines, increased penetration of wind energy on some electricity grids, and their impacts on the associated bulk wholesale power markets. More analytical work in both economics and electrical engineering that includes the specifics of the market structure and the unique features of the Irish electricity landscape is required. The establishment of an all-island market seems a reasonable pursuit and has been topical of late although firm timescales and legislation have not been established.

For intermittent generators the notion of ancillary service provision is critical (especially in the Irish system where generation adequacy is an issue and where the CER intend to implement a "causer pays" attitude towards funding reserves). The ability of wind energy to provide for various ancillary services, or a need to secure them in a market is indicated by Hirst [22]. He identifies that wind energy in most cases will ideally have recourse to buying these services, which include: regulation, load following, spinning reserve, black start, and voltage control. A new market structure that explicitly provides for the fair and transparent treatment of all generation, including intermittent generation, will need to be informed by recourse to international experience over the last decade. Ideally the market evolves into one with liquidity in the spot, ancillary services, and derivative markets. In this way the stochastic nature of wind energy can be addressed on various temporal bases and hedged appropriately.

Figure 7 below shows the estimated amount of reserve needed to operate the Irish system over the next forecast period in such a way as to have reliability of the system equal to a predetermined acceptable level (this acceptable level is a policy decision) [23]. The reliability of the system is measured by the number of load shedding incidents (LSI) tolerated per year. 
Fig. 7: System required reserve level for one hour and different numbers of load shedding incident per year against increasing wind power penetration [23]. The wind forecast is 3 hours ahead.

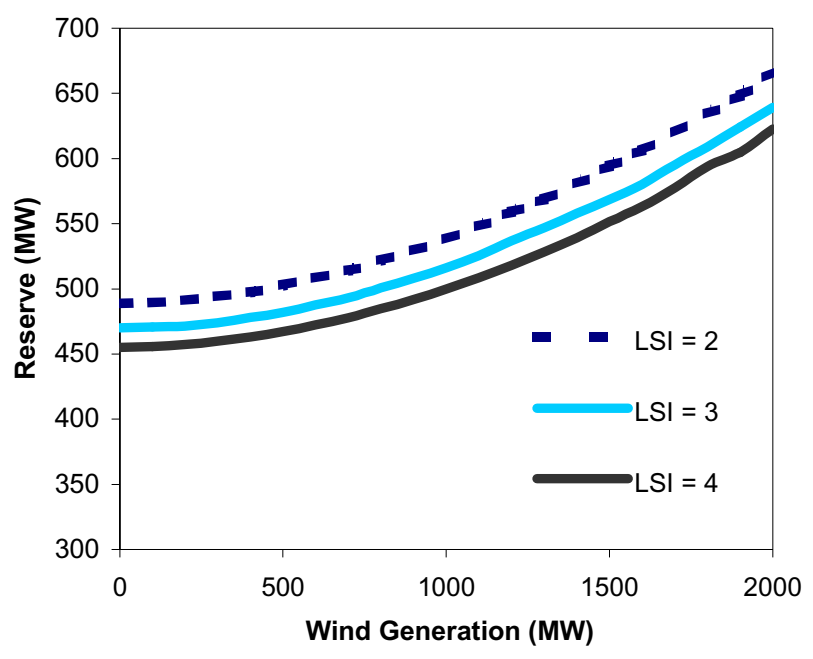

It should be noted that in the proposed Irish market there will be a market for reserves, thus the price paid for reserve will vary depending on the time of day, week, year etc.

Hirst [22] [24] has quantified the load following and regulation costs attributable to the stochastic nature of the wind energy output for a number of different US utilities. The market structure and generation mix make these analyses impossible to translate into the Irish context. Nevertheless in most cases the costs of providing these services was minimal. The costs of regulation in the Pennsylvania, New Jersey and Maryland (PJM) market was of the order of 530 eurocent/MWh.

\section{GRID ISSUES}

The requirements of wind farms are inherently different than typical large scale centralized thermal power stations. Outhred [25] describes some of the principal distinctions succinctly. Wind resources are time-varying and nonstorable, therefore wind farm output is non-dispatchable except at the cost of spilling wind resources. The generators used in modern wind turbines often employ doubly fed induction generators with power electronic interfaces. Other design options are a low speed alternator connected to a variable frequency inverter or a constant speed, directly connected induction generator. Wind turbines start and stop when the wind speed reaches cut-in and cutout speeds respectively, with associated transients that depend on the technology and control algorithms employed.

The interaction of wind energy and the grid has emerged as a potentially significant obstacle to increased penetration. There are issues ranging from operating reserves and frequency control to the ability of the current grid system to accommodate additional generation. A number of studies have been undertaken in Northern Ireland and the Republic to investigate these issues [13], [18], [23], [26], [27], [28]. Of particular interest is a paper by Doherty et al. [29] that summarises the results of two recent studies into the impacts of increased wind penetration on the island of Ireland [18], [28].

Extensive inroads into the dynamic modelling of wind turbines have been made by Slootweg and Kling summarised in [30]. The Irish grid system operator is currently involved in evaluating the suitability of models for use in power system dynamic studies [31]. Both of these papers [30] [31], illustrate the need for the development of better models so that system operators can study in advance the consequences of large-scale penetration of wind generation onto the grid.

The grid code specifies the planning code and connection conditions, the operating codes, scheduling and dispatch codes and general conditions for all generators on the Irish system. However, the grid code was drafted at a time when there was no wind generation in Ireland. Since the grid code imposes the same conditions on all generators it poses some difficulties for wind generators connecting to the distribution and transmission system. The ESB in a draft grid code for wind farms specifies technical requirements in categories including: power control, power ramp limits, power 
factor, voltage control and range, voltage dip, harmonics, and frequency control and range. Denmark, Scotland, and Germany (among others) are also in the process of developing and refining wind farm specific grid codes. There is an acceptance of the need for grid code changes and for the necessity of wind turbine technology, where possible, to provide ancillary service [32], [33].

In Ireland, most wind turbines are constant speed, directly connected induction generators. Constant speed induction generators are a potential threat to voltage stability [31] [34]. Unlike constant speed generators, variable speed turbines can control their rotational speed in response to changing wind conditions, and this ability greatly reduces the large variations in power experienced with the fixed speed design. Variable speed turbines also allow for increased energy capture at low wind-speeds compared with constant-speed designs. By allowing the rotational speed of a windturbine to vary, the speed increases slightly during a gust and the resulting electrical power is effectively filtered by the large inertia of the turbine. This is in contrast to the operation of a constant speed turbine where, due to the very limited speed variation, any fluctuations in captured wind-power are transferred almost directly into electrical power. Directly connected generators have little or no frequency control features, no internal control of reactive power and they deliver no sustained fault current. When a system has a large number of constant speed directly connected induction generators they can seriously reduce the voltage stability of the system [31]. Looking into the future, Ireland should seek to install variable speed turbines that allow some level of control of both active and reactive power.

A critical issue for wind generation and any proposed grid code is the requirement that wind generators have the ability to stay connected to the system after a fault i.e. fault ride-through capabilities. Currently many wind turbines have protection equipment installed which disconnects the turbine following a fault [29]. This sympathetic tripping can cause serious problems for system security, increasingly so with larger numbers of wind generators connecting to the system. Essential, this sympathetic tripping aggravates a fault event resulting in increasing pressure on ancillary services and reliability standards. In periods of low demand and high wind speeds (e.g. during windy nights) a significant contribution of wind power can be reached even when the overall share of wind power in the electricity supply is still modest. When the wind power penetration level is considerable it will no longer be feasible for wind turbines to disconnect during voltage or frequency disturbances, as this would lead to a large generation deficit [30].

There are a number of areas in the Republic where the electrical grid can accommodate new generation. A recent report by the Transmission System Operator describes these figures for the $110 \mathrm{kV}$ network (Fig. 8)

Fig. 8: Capacity for New Generation (MW) in Ireland at 110kV stations in 2006 [12].

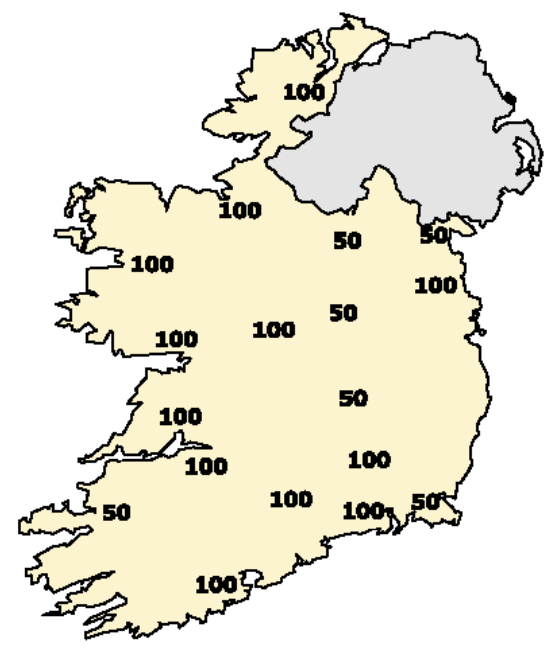

In the forecast statement (2003) [12] there is also a quantification of the relative robustness of the grid from a short circuit current perspective that may be used to indicate areas where wind farm implementation will require upgrades or voltage control.

One policy is being developed to mitigate against excessive connection costs for individual wind farms. It is known as the grid upgrade development programme, and is designed to provide for shared costs of network connection fees. The Steering Group concluded [35] that the grid upgrades should be planned by reference to perceived demand for shared infrastructure. The perceived demand should be based on clusters with two or more projects with full planning permission intending to connect to the upgrade. The prioritisation of clusters for investment support should operate on 
a first come first served principle. It is proposed that each developer connecting to the transmission network under this programme would pay a proportion of the cost of the common connection equipment (in proportion to their output) as well as $100 \%$ of the costs for connecting the development into the common connection equipment. It is anticipated that the fund would be a revolving one i.e. revenue recovered by the network operator from the connecting parties funding the common connection equipment, would be used to finance future connection equipment at other clusters. The network operator will be "kept whole" through revenue received from Transmission Use of System (TUoS) charges on all customers.

\section{CONCLUSIONS}

This paper serves as a contextual outline of some relevant issues in wind deployment in Ireland. It has been established that various issues surrounding the interaction between wind energy and the electricity network are some of the more formidable obstacles to increased deployment of wind generation. There is a requirement to address these in a rigorous manner based on detailed analysis. While high levels of penetration are feasible without significant system reinforcement [12], there are many technical challenges which need to be overcome before they can be realised. These challenges include, fault ride through capability, development of robust and reliable models for use in power system studies, novel operating methodologies and changes to grid codes, practices and regulatory structures. These challenges are all surmountable but need to be done in a cost effective and timely manner in order to facilitate the deployment of large amounts of wind generation in a timely manner.

\section{References}

1. Department of Public Enterprise, Green Paper on Sustainable Energy. 1999.

http://www.dcmnr.ie/display.asp/pg=557

2. Directive 2001/77/EC of the European Parliament and of the Council of 27th September 2001 on the Promotion of Electricity Produced from Renewable Energy Sources in the Internal Electricity Market. Directive 2001/77/EC. 2001. http://europa.eu.int/scadplus/leg/en/lvb/127035.htm

3. European Commission, Energy for the Future: Renewable Sources of Energy, White Paper for a Community Strategy and Action Plan. 1997.http://europa.eu.int/scadplus/leg/en/lvb/127023.htm

4. Department of the Environment and Local Government Ireland, National Climate Change Strategy Ireland. 2000.http://www.environ.ie/doei/doeihome.nsf?Open

5. Department of Communications Marine and Natural Resources Ireland, Results of the Sixth Alternative Energy Requirment (AER VI) Competition. 2003(Department Publications).http://www.dcmnr.gov.ie/

6. Commission for Energy Regulation (CER), Best New Entrant Price 2003. CER/02/242, 2002. http://www.cer.ie/cerdocs/cer02242.pdf

7. Commission for Energy Regulation Ireland, Public Service Obligation Levy, Proposed 2004 Charges. CER/02/151, 2003.http://www.cer.ie/cerdocs/cer03151.pdf

8. Sustainable Energy Ireland (SEI), Energy in Ireland 2002. Energy Policy and Statistical Support Unit, 2002

9. Helm, D., Energy Policy: Security of Supply, Sustainability and Competition. Energy Policy, 2002, 30, pp. $173-184$

10. $\quad$ ESB National Grid, Generation Adequacy Report. Dublin, Ireland, 2003

11. ESB National Grid, Adverse Trends in Power System Availability. A TSO Advisory Note, 17 July 2003

12. ESB National Grid, Forecast Statement 2003-2009. Dublin, Ireland, 2003

13. Hurley, T. and R Watson. An Assessment of the Expected Variability and Load Following Capability of a Large Wind Penetration in Ireland, Proceedings of Global Wind Power Conference. 2002, Paris, France

14. DKM Economic Consultants, Costs and Benefits of East-West Interconnector between the Republic of Ireland and UK Electricity Systems, 2003.

15. Statutory Instruments, Electricity Regulation Act 1999. 1999(S.I. No 214)

16. European Union, Directive 96/92/EC of the European Parliament and of the Council of 19 December 1996 Concerning Common Rules for the Internal Market in Electricity, 1996.

http://europa.eu.int/comm/energy/electricity/legislation/amending_legislation_en.htm

17. Arnott, I. Intermittent Generation in the National Electricity Market, Proceedings of Australian Wind Energy Agency. 2002, Adelaide

18. Garrad Hassan, Impact of Increased Levels of Wind Penetration on the Electricity Systems of the Republic of Ireland and Northern Ireland: Final Report, 2003, Commission for Energy Regulation/OFREG NI.

19. Commission for Energy Regulation Ireland, The Treatment of Green Supplier's and Generator's Balancing Requirements under the Trading and Settlement Code, Decision Paper. CER/03/071, 2003. http://www.cer.ie/cerdocs/cer03071.pdf 
20. Commission for Energy Regulation (CER), Review of Market Prices, A Decision by the Commission for Energy Regulation. CER/02/113, 2002 http://www.cer.ie/cerdocs/cer02113.pdf

21. Commission for Energy Regulation Ireland, Market Arrangements for Electricity (MAE) - An MAE

Consultation by the Comission for Energy Regulation Under S.I 304 of 2003. CER/03/230, 2003.http://www.cer.ie/cerdocs/cer03230.pdf

22. Hirst, E., Interactions of Wind Farms with Bulk Power Operations and Markets. www.ehirst.com, 2001

23. Doherty, R. and M. O'Malley. Quantifying Reserve Demands Due to Increasing Wind Power Penetration, Proceedings of Proceedings of 2003 Power Tech Conference. 2003, Bologne, Italy

24. Hirst, E., Integrating Wind Energy in the Bonneville Power Administration (BPA) Power System. www.ehirst.com, 2002

25. Outhred, H. Some Operation and Investment Issues for Wind Farms in a Restructured Electricity Industry, Proceedings of ANSZES Proceedings. 2002, Adelaide

26. Econnect, The Impacts of Increased LEvels of Wind Penetration on the Electricity Systems of the Republic of Ireland and Northern Ireland, 2003, Response to CER from Airtricity.

27. Persaud, S., Wind Power Variability and Power System Operation, 2003, Queen's University: Belfast.

28. Department of Enterprise Trade and Investment and The Department of Public Enterprise, Final Report on North/South Energy Studies. August 2001.www.energy.detini.gov.uk

29. Doherty, R., et al., Wind Penetration Studies on the Island of Ireland. Wind Engineering, 2003, this issue

30. Slootweg, J., G, Modelling Wind Turbines for Power System Dynamics Simulations: an Overview. Wind Engineering, 2003, this issue

31. McArdle, J., Dynamic Modelling of Wind Turbine Generators and the Impact on Small Lightly Interconnected Grids. Wind Engineering, 2003, This issue

32. Causebrook, A. and B. Fox, Decoding Grid Codes to Accommodate Diverse Generation Technologies. Wind Engineering, 2003, this issue

33. Johnson, A. and H. Urdal, Technical Connection Requirements for Wind Farms. Wind Engineering, 2003(this issue)

34. Smith, P. Impact of Increasing Wind Generation on the Transmission System in the Republic of Ireland, Proceedings of Symposium Neptune CIGRE. 1997

35. Commission for Energy Regulation Ireland, Funding of Grid Upgrade Development Programme for Renewables, Consultation Paper. CER/03/016, 2003.http://www.cer.ie/cerdocs/cer03016.pdf 